\title{
Comparison and Reference on Chinese and American Preferred Stock Issuance System
}

\author{
Ya TAO \\ School of accountancy, Inner Mongolia University of Finance and Economics, Hohhot, 010051, China
}

\begin{abstract}
Preferred stock is a mixed financing tool which risk is less than ordinary shares, but income is higher than bond. It has an irreplaceable position in the field of investment and financing, and has great demand of market. Western countries generally use the preferred shares, especially in America. Preferred shares have a long history, so it owns a complete relevant legislation, advanced system and it is worthy of our reference. However, the preferred stock in our country is still in the trial stage and the related system is not perfect at present. In order to give full play to the advantage of financial instruments, it is necessary to explore the specific strategies of preferred shares in China.
\end{abstract}

KEYWORD: Preferred stock; Comparison; Reference; Strategies

\section{THE OVERVIEW OF PREFERRED STOCK}

\subsection{The connotation, characteristics of preferred stock}

Preferred stock is a hybrid securities of both stock and bond properties which is relative to the ordinary shares, but has precedence over the rights in profit sharing and distribution of residual properties.

The preferred stock has following characteristics: the dividend rate is fixed, in general, it cannot participate in dividends, but can be obtained dividends before common stock, it without dilution control; preferred stock has little rights scope, shareholders do not have the right to vote or to be elected, but have limited voting rights; when company make the liquidation, preferred shareholders can get back rest assets of company before common stock; preferred shareholders cannot withdrawal, they can only be redemption through the redemption terms of its preferred stock.

\subsection{The function of preferred stock}

In the long term, the introduction of preferred stock will enrich the Chinese capital market level, enrich the varieties of securities and promote the stable development of the market; the introduction of preferred stock into commercial bank's tier one capital can reduce the core tier one capital adequacy requirements, reduce bank common stock financing pressure greatly, so as to enhance flexibility in capital operation; at present, in the situation of listing Corporation has "alone big" , if ordinary shares can be partially converted into preferred stock, it will be conducive to improving the corporate governance structure, enhance the performance of the company; Chinese economy is in a critical period of the whole industrial structure adjustment and transformation and upgrading, enterprise merger is an important path to achieve structural adjustment, so as a supporting financing tools, the implementation of preferred stock will help the merger and reorganization of enterprises, promote the integration of the industry.

\section{ANALYSIS OF THE DEVELOPMENT OF USA PREFERRED STOCK}

In the early $1830 \mathrm{~s}$, America began to pursue the preferred stock, which still has a relatively good development trend until today.

\subsection{The development and changes of preferred stock market value}

We can see that the preferred stock market value of America has always been in a steady change since 2000. However, during the financial crisis, the total preferred stock had a significant growth, because the preferred stock had become the main financing tool. As of the October in 2013, the liquidation value of active preferred stock in the USA market was up to $\$ 390$ billion. 


\subsection{The condition of preferred stock structure}

The top 5 issuers of USA preferred stock are as follows: Fannie Mae, Freddie Mac, American Bank, USA Wells Fargo and GM. They issued a total of $\$ 266.3$ billion in preferred stock, which accounted for $70 \%$ of the total scale of the preferred stock market, including that Fannie Mae issued \$136.3 billion in preferred stock, which accounted for $36 \%$ of the total scale of the preferred stock market.

And that the preferred stock of financial companies accounts for $84.2 \%$, which plays the absolute leading role. Utilities accounts for more than $4.7 \%$, and other communication, consumer goods industry also issue preferred stock but accounts for the less. Therefore, the preferred stock plays an important role in the American financial market.

\subsection{The dividend rate of preferred stock}

The dividend rate of the preferred stock is the main index to reflect the return conditions of preferred stock, which is the agreed rate when the company issues preferred stock. The dividend rate of the preferred stock in America has always been relatively stable and is higher than the rate of the same period of long-term treasury rate. Since 2000, the dividend rate of the preferred stock of America has small amplitude fluctuations from $6 \%$ to $9 \%$. In the same period, the USA rate is in the range of $2 \%$ to $6 \%$, and the common stock dividend rate fluctuates from $1.5 \%$ to $3.5 \%$. The British preferred stock dividend rate is between $4 \%$ and $10 \%$, which has larger fluctuations as for the USA, but most of the time it is still higher than the same period in bond yields and the rate of ordinary shares. Therefore, the preferred stockholders are considerable.

\section{PREFERRED STOCK SYSTEM COMPARATIVE ANALYSIS BETWEEN CHINA AND THE UNITED STATES}

\subsection{The comparison of historical development}

In America, preferred stock produces in the nineteenth Century 30's, accompanying by railway construction boom gradually. The railway companies raise funds from the public investors and the government through preferring shares of the issuance, so as to solve the huge demand of funds for railway construction. In nineteenth Century 50 years, preferred stock has been widely released and it is actively traded in secondary markets. At the end of nineteenth Century, the preferred stock market is fully developed, especially in enterprise merger tide, it played an important role and helped promote the industrial integration and heavy industrialization of USA. At the end of twentieth Century, the preferred shares gained widespread innovation, widely used the conversion right, the foreclosure sale right, and common terms, combining it with risk investment and supporting the development of start-ups and the rise of emerging enterprises America and complement of transition economy. During the global financial crisis, the preferred stock has become a major tool to implement the financial rescue plan. For example, in 2008 October, the government announced a $\$ 125$ billion purchase of USA with nine major bank preferred shares of financial institutions, including Citibank, JP Morgan chase and so on, improving the capital adequacy ratio.

In China, common stock has been a champion for long time, although preferred stock had appeared in Chinese history, people did not 1 widely pay attention to it. In early twentieth Century 80's Chinese, participating preferred stock shape appeared, and several domestic companies attempted to issue preferred shares at the end of the 80's, including Jinbei Automobile and Tianmu pharmaceutical, but these enterprises transfer preference shares into ordinary shares soon .

\subsection{The comparison of relevant legislation}

In western countries, especially in America, company law formulated preferred shares clear, which will be an important basis for the distribution and usage of preferred stock. The Delaware is the most important jurisdictions of America corporation law, and most listing Corporation USA institution are located here. Therefore, "Delaware state Ordinary Company act" , for example, the provisions in section 242nd point that preferred shareholders as a category shareholders in the special case have the right to vote of revision of the articles of association of the company, and the "special circumstances" here mainly refers to the articles of association of the company may make a bad effects on these shareholders' priority or special rights. In addition, the "standard business corporation law" has a similar provision on the stock.

In China, the beginning of twentieth Century in 90, joint-stock construction gradually standardized. The state promulgated a series of laws, also clearly clarify the common and preferred shares, which "Limited by Share Ltd legal norms" describe the preferred stock most comprehensive, however, this law is only the Department Rules, it does not have high legal effect, while the authoritative "company law" does not formulate clearly of preferred stock system, so there is no enterprises who can fully understand and use the financial tool. Although in 2006 the words preferred stock appeared again, but this was just a flash in the pan, and it did not arouse widely know. 


\subsection{Comparison of preferred stock system}

\subsubsection{Limiting conditions}

American corporate law embodies the characteristics of authorized legislation, which means substantive and procedural issues will not be issued, and this important characteristic give the shareholder and the company rights to come to an agreement of various special rights or obligations preference shares of according to their need. The United States make their own company law for each state, the provisions of each are not identical, but these corporation laws have a lot in common---the provisions of the preferred stock is the basic authorization but not mandatory.

The issuer of preferred stock in our country has been given a specific range, but preferred stock for limited liability companies and small scale non listed Limited by Share Ltd, it did not make clear provisions. Shareholders of limited liability companies have rights to request the new designed dividends, share the right of appointment and vote through the agreement or the articles of association of the company, while the small scale of non listed Limited by Share Ltd shareholders can design the right to request the allocation of profits by the articles of association of the company itself. In addition, limited liability companies and small scale non listed Limited by Share Ltd have no rights to issue preferred shares with other rights. This is different from the will of the American homemade principle, allocation of rights and obligations of governance structure and the principle of limited liability company and the Limited by Share Ltd in China have been strictly limited, so it is difficult for shareholders to in the articles to make arrangement of association of the above content according to their own wishes.

\subsubsection{Specific system}

America's reasonable system plays a vital role to issue preferred shares and make investment of both stable profit. For example, the provisions in venture capital contract, investors who invest in preferred stock risk can receive priority dividends, which protect the rights and interests of investors; in venture enterprise will usually give preferred shareholders rights to elect a certain number of directorships of preferred shareholders, and veto power to the important items of the company and so on.

In China, preferred shareholders do not have the right to participate in the company management, which means the preferred shareholders do not have the right to vote. It is easy to cause the unreasonable corporate governance structure and forms the right centralized mode, if the shareholders have no right to intervene in management of the company, so if you want to issue preferred shares well, it is inevitable to set up a set of impeccable system.

\section{COUNTERMEASURES AND SUGGESTIONS OF OUR ISSUED PREFERRED SHARES}

From the positive impact of American issuance of preferred stock, it is not difficult to find that the preferred stock implementation will also bring China many opportunities. In order to promote the development of Chinese capitalism market and consummate the capital structure of listed company, preferred shares should be carried out to exploit its advantages at present, thus it is particularly important to establish a perfect system.

\subsection{The macro aspect}

\subsubsection{To improve the legislation system of preferred stock}

We should learn from American issuance of preferred stocks, to make clear provisions in the law, especially give a clear indication whether a limited liability company can issue preferred shares in the Corporation Law, and make a specific description on the profit distribution and the distribution of residual property rights. The by-laws and operation instruction which related to the system of preferred shares should be issued. To aid both parties of investment by universal legal document.

\subsubsection{To formulate explicit and reasonable terms}

The rules of the American preferred stock system is flexible with less restriction, we should draw lessons from such experience. Preferred stock should be flexible designed, it can be attached to call or put option and afford investors more choices. And we should make the corresponding provisions to protect the interests of investors. Towards different enterprises should have different provisions, it cannot be biased. The greater the risk enterprises enjoy the privilege which should be increased relatively. Especially for the limited liability company and small-scale unlisted limited company should be treated differently. On the one hand, it can be appropriate to relax the limitation of issuing category and share of preferred stock of this kind of enterprise. On the other hand, the company should rationally determine the mode of governance structure and the distribution of rights and obligations.

\subsubsection{To strengthen financial supervision}

Wide implementation of preferred stock is a great innovation of our country. Although this innovation will bring many benefits, it also has many risks. At present, an important feature in the developing stage 
of market economy in China is accompanied by the process of system transition, and this process will be short of clear and effective rules. If the financial innovation emerges problems, it often brings a wide influence. Therefore, how to handle the relationship between financial innovation and financial regulation is very important.

\subsection{The microscopic aspect}

\subsubsection{To confirm the reasonable issue price}

We should ask the price together with the medium and small investors and institutional investors, so we can choose online and offline synchronous inquiry method, If institutional investors put forward the issue price of new shares is low, medium and small investors can improve the over-subscription magnification through their purchase way. So that the demand will increase and the prices will go up. This way can prevent the low inquiry results from institutional investors inquiry results; if the issue price of stocks which proposed by institutional investors is too high, the purchase oversubscribed rate of small and medium-sized investors will be reduced, so it can avoid inquiry results of institutional investors is too high. This establishes a balancing relationship between institutional investors and general investors which can used to determine a reasonable price.

\subsubsection{To determine the dividend rate}

The dividend yield is the ratio between the dividend and stock price. In investment practice, the dividend yield is one of the important measure of whether the enterprise has the investment value. Therefore, if enterprises want more investors to tend to buy preferred stock, the enterprises should determine a reasonable rate of dividend on preferred stock. Non public issuance of dividend rate of preferred stock shall not be higher than the two most recent fiscal year annual weighted average yield of net assets, after making a decision about this interval, the companies and principle underwriter should consider the related influencing factors, and then determine the nominal preferred stock dividend rate in the interval.

\subsubsection{To limit the quantity of preferred stock}

At present our country has begun pilot issuance of preferred stocks, especially many banks, insurance agencies itch for a try. If a company has significant changes, there will show up some surplus profit distribution, the preferred shareholders have the rights to vote. If the excessive number of preferred stock is bound to affect the common equity of shareholders equity, it's easy to cause the conflict, which is not conducive to the development of the company.

\subsubsection{To reasonably increase preferred stock}

China can draw on American preferred stock to increase income, especially trust preferred shares. Moreover, if the companies want to make investors willing to buy preferred stock, they can provide the certain function to the preferred stock, such as the issuance of convertible preferred stock. But the amount that can be converted to ordinary shares of preferred stock should be limited to a certain percentage of the ratio, the ratio should be the one between convertible preferred shares and the holders of preferred shares.

\section{SUMMARY}

Through the comparison of the differences of SinoU.S in the implementation of preferred stock, we can see clearly that the preferred shares is more effective than common stocks of financing, it can give China's stock market new chance. Facing of real estate bubble burst of China and the increasingly intense competitive environment, China must change the situation of weak current stock market to maintain the national economy fast, healthy development. The introduction of preferred stock is not only a great help to promote the role of the doldrums of stock market of our country at present, and it also can help our transition of economic system and the restoration of market financing function of resource allocation, furthermore, it has far-reaching significance of perfecting the stock market mechanism and reviving investors' confidence.

\section{REFERENCES}

[1] Wang Hanfeng, Li Qiusuo.2014. Preferred stock: an important step to promote the construction of multi level capital market. Investment and Securities. January.

[2] Xue Leirong, Zhou Wenyuan. 2014. Detailed analysis of preferred stock pilot and its influence on the bond market. Investment and Securities. Eighth.

[3] Xu Yanfang, Chen Zhouyu. 2009. The United States preferred stock practice and introducing the realistic meaning. Twenty-fourth. 